\title{
Ethics and embryos
}

\author{
Nicola Poplawski and Grant Gillett University of Otago, Dunedin, New Zealand
}

\section{Authors' abstract}

In this paper we argue that the human form should be seen to exist, in a longitudinal way, throughout the continuum of human growth and development. This entails that the moral value of that form, which we link analytically to the adult, interacting, social and rational being, attaches to all phases of human life to some extent. Having established this we discuss the consequences it has for the moral status of the human embryo. We then apply this argument, and the resulting moral status, to the area of reproductive technology. In doing this we show that there are certain regulations and controls which ought to apply to the use of these infertility treatments.

We have a strong intuition that human life of whatever stage has moral significance. Some argue that this is 'speciesism', in the same way that others direct accusations of racism when the claim is made that a greater moral significance should be placed on white human life as opposed to non-white. However, the claim for such moral significance need not stem purely from being a member of the species Homo sapiens. The claim may rest on the quality of human functioning which, in terms of conscious appreciation, interactions and behaviour, has moral weight over and above other biological life. The difficulty is that some human beings, including fetuses and embryos do not have these properties.

\section{Potentiality}

The standard potentiality argument argues that despite the fact that embryos do not have the properties now, they have the potential to develop them. They claim that if an embryo has the potential to be a person with 'the right to life', the right to life should apply before the 'stage' of being a person is reached. Thus they argue from the premise that one type of creature will change into something different $t o$ the conclusion that a creature of the first form has the moral properties of the second form. This is a 'consequentialist' view of potentiality. On this view, potential is not an inherent

\section{Key words}

Embryos; status of embryos; reproductive technology. property of the entity. It is a projection of an anticipated future state, onto the current entity; but that future state may or may not eventuate.

But there are many problems with this view of potentiality. First, it makes little sense to give an embryo rights that it may have at a later stage unless its potential is an inherent property which confers those rights. Surely we should form attitudes to things on the basis of what they are rather than what they might be? Second, there is the distinct possibility that any given embryo will never reach the stage of having those rights. But many embryos which spontaneously abort are no different from ones that will reach the potential later stage. Why should they have different properties? Third, just how far back ought these rights to be extended; should sperm and ova be included? (If so we ban contraception.)

Clearly potentiality needs somewhat more analysis and justification or it must be discarded altogether.

We will give a more Aristotelian analysis (1) and argue that the form of a human being extends beyond that present at a given slice of time to take in the breadth of an entire life. There is a phase of development, a phase of moral engagement with others and a phase of dying (which may be abrupt or more drawn out). On this view, the process of becoming a person is a progression through a series of linked developmental stages. Because each stage is an essential component of the whole, the form of $N$ humanity involves a life with a characteristic longitudinal 'shape'.

At one stage of this whole, the individual becomes a rational social being and an inherent moral value is realised. We then take this moral value, inherent to human beings as rational social beings (persons), and attach it to the form as a whole.

To do this is to evince a feature of our general reasoning. In the main, we look at a thing not only as what it is in itself but also in view of what it is part of. For example, a gunshot has different significance as part of a clay target shoot than as part of a murder. Thus we derive the moral status of an embryo from the whole of which that embryo is a part. An embryo has present applicable rights not because some time in the future that embryo may become a person with rights? appropriate to persons but because it is the same 
individual who becomes a person. We accept that the embryo has these rights because as a phase of the human form, it has some claim to the rights we accord to persons.

Now we must clarify when an embryo first has rights, what those rights are and how much moral weight they have, especially when they are in conflict with the rights of other persons.

\section{Rights}

What is a right? 'Essentially, rights are justified claims that require action or restraint from others - that is, impose positive or negative duties on others' (2).

The debate surrounding rights concerns both natural rights, which are contentious, and constitutional/legal rights which exist (without doubt) in our society because we have created them.

At present, British and New Zealand legislation gives limited constitutional rights to embryos and fetuses. For example, a fetus is protected from abortion unless certain legal criteria are met (3). Religious and anti-abortion groups give an embryo certain rights which they believe to be implicit in its existence. These rights, it is claimed, do not require a law or act of parliament to create them, they are therefore natural rights.

In the debate surrounding the status of embryos the concept of natural human rights seems, clearly, to be important and we must therefore spend some time clarifying it. Such rights could either be God-given or intrinsic to the nature of human beings. In either case, one would need to reason about the lessons to be learnt (from creation/nature or from 'revealed laws') to develop a substantial conception of the moral rights concerned.

John Locke and his followers espoused natural human rights on the basis of secular thought. In this tradition, Hart claims that if there are any moral rights 'there is at least one natural right, the equal right of all men to be free' (4). This is close to Kant's view that all men have the right to be fully-functioning, autonomous agents. For pro-lifers, every human being also has a right to life and therefore should not be killed. Both stands appear to be based on a set of moral intuitions. However, such intuitions conflict, so they cannot provide sufficient grounds on which to assert that such rights exist.

Bentham and other utilitarians claim that natural rights are nonsense and that they exist purely as figments of our imagination $(5,6)$. Non-utilitarian objections to moral rights are based either on the belief that codified, and therefore non-natural duties alone exist, or on scepticism about the possible source of moral rights. The extreme sceptic denies that in a state of nature any creature has rights. Therefore, questions arise as to whether natural/moral rights have been correctly identified and where they come from. If one could find a general basis for natural rights then one would be able to see whether embryos or fetuses fulfilled the requisite conditions to be credited with them.

The view favoured by the present authors is that natural rights arise when it goes against the intrinsic nature of moral thinking or moral agency to deprive an individual of the claim concerned. If compassion, for example, were seen to be at the heart of moral judgement in general, it follows that to act without it would be to fail in respect to one of the basic features constitutive of moral conduct (7). We would argue that moral considerations arise in contexts where individuals interact with each other and develop reciprocal attitudes which guide their behaviour. These attitudes embed a sensitivity to the needs and vulnerabilities of others and involve a kind of empathy which informs actions which impinge upon what matters to others. Therefore, we internalise the norm that we should avoid, wherever possible, harming another person.

We combine this with the view that the potential to be a person is inherent in the whole (longitudinally realised) form of a human being. This implies that a human being, simply by having a form which at some stage will participate in moral interactions, has a right not to be the subject of gratuitous insult or injury.

\section{The concept of longitudinal form}

There is little doubt in most people's eyes that at some stage human beings have moral value. (We discuss this further later.) The difficulties arise when we endeavour to pinpoint when this stage is reached. However, if we look at the human form in a longitudinal way this problem becomes more tractable.

One can make an analogy with the colour spectrum. It is not possible to identify the exact point where one colour emerges from another because there are gradual transitions through a series of shades. Red emerges from an increasingly red shade of orange; it cannot be said to appear at a definable point. Thus, though distinctions can be made, real continuities still exist.

The adult, adolescent, child, viable fetus, pre-viable fetus, embryo, blastocyst and conceptus are similarly part of a continuum. It is not possible to determine the exact point separating adjacent stages. For this reason we cannot look at any point in the developmental process in isolation when attributing moral properties; we should look at the human being as having a single form which exists over time. Development is, therefore, a process whose overall nature may have distinct moral significance. The conceptus begins this process and the 'form' which not only governs the process but also makes it morally significant, is realised as time goes by.

Note that this view may confer some moral worth on the embryo even at fertilisation. If the initial stage in the human process does not occur none of the later stages can be reached and therefore this first stage is an essential component of the complex whole in the same way that the laying of foundations is the essential first stage of building a house. Who can say that any one stage of building a house is any more important than 
another when without all stages one has nothing? The conceptus may have moral significance because it is an essential component of the total longitudinal form of a morally signficant being (we will consider a modification of this derived status below).

The total form of a human being exists through time. We can also say that a single individual makes up that form throughout its temporal existence. Therefore, if we can justify a moral value for that individual at one point in time, that moral value ought to be conferred on the total form throughout its temporal existence. Remaining consistent to our argument we analyse problems at all phases of that form with the same moral precepts. But, even though the moral value is the same this does not entail that the moral analysis will bring about the same conclusions.

\section{The person as valuable}

For Kant a person has 'rational willing agency as the essential characteristic' (8); for Locke 'the ability to think combined with self-awareness over time is the essence of personhood' (8). Both formulations exclude very young infants and humans with severely damaged or defective brains from the category of persons. This exclusion seems to go against our intuitive feeling that there ought to be some value at least placed on the lives of infants.

Such feelings are admittedly not reliable indicants of moral value (remember the feelings of Americans in the 'deep South' to black Africans), but they do give us a prima facie reason for questioning the validity of an exclusive definition of personhood. They also confirm the broadly Aristotelian view we have favoured because embryos, fetuses and infants are phases of beings whose form is such that they are to be valued as persons. (In the case of the severely brain-damaged we do not have the same metaphysical support for our intuitions based on potential, indeed the intuitions themselves are less clear.)

But, when does this human form, which is to be valued, begin?

In moral history a number of beginning points for human form have been considered. Quickening (at approximately twenty weeks gestation) is thought by some to be the first signs of personhood. This may be because the first fetal movements felt by the mother are thought to indicate ensoulment, or because such manifestations are the first communication between the mother and fetus. Birth is important to others (for example Engelhardt) for similar 'interactive' reasons. Engelhardt argues that, although a newborn infant has not yet become a person (as a subject of selfawareness), he/she expresses rudiments of human nature in interpersonal interactions (which include a form of communication) and is extended the right of membership of a social group because of that interaction (9). Perceived membership of a moral community, on this view, gives some rights to the infant, including the right to life. The viability criterion could be favoured for much the same reasons - the fetus has reached a stage in development where it could survive ex utero in a human environment. It therefore has the rights of any individual who can and does interact in that environment. On this basis the viable fetus is credited with certain rights because it has a capacity for what is crucial in moral communities not because it currently expresses that capacity (note that the newborn infant is still dependent for viability on the human supports around it).

Let us accept that interaction in a human context (even if it is not fully reciprocal) places moral value on the life of the subject under consideration. But perhaps that morally significant interaction occurs much earlier in the gestational process than claimed by any of the arguments above (this would imply that the interaction does not have to be of an interpersonal type (10)).

\section{What type of interaction is significant?}

We have accepted that it is the degree to which a developing embryo or fetus becomes embedded in a human community which determines moral dues or rights. (This is congenial even to Kuhse and Singer (11).)

When the blastocyst begins to implant approximately six days after fertilisation - a physical interaction between one individual (the mother) and another (the blastocyst) begins. As development continues this physiological link becomes both stronger (12) and more obvious. First the woman realises that she is pregnant, then the father, relatives and friends are informed, eventually even complete strangers will know of the pregnancy due to the physical appearance of the woman. As these outward changes in appearance occur, so too do inward changes. At the end of the eighth week of gestation all the major structures and organ systems are developing and electroencephalogram (EEG) activity is first detectable. At this stage a recognisable physical form has been reached. The first movement of the fetus is felt by the mother at approximately 20 weeks. This brings a special and traditional meaning to the progressing pregnancy as it gives a sign to the mother, exclusive of medical technology, that the developing fetus is alive and growing inside her. By the 26-28th week of gestation the lungs are sufficiently developed to be able to breathe air and the fetus would be able to survive in the external environment. (At this stage the desire of the woman to terminate her pregnancy is in practice separable from the potential for the baby to survive.)

In the usual course of events, as this fetal development occurs there is a gradual increase in the hopes and expectations of parents, relatives and friends as it becomes increasingly more certain that a baby will soon be 'joining the family'. Thus, a very special place is created in a community for the developing individual long before it has arrived 'on the scene'. This preparation of a social 'niche' establishes the fetus in an interpersonal and social context and further highlights the developing interaction which is present even before 
birth has occurred. From the point of viability the fetus is able to be born and participate, not just as a 'potential baby' but as an actual, identifiable individual in the social community.

After entering that community, at birth, the individual gradually develops the ability to communicate, conceptualise and rationalise. Thus she has a place in the moral system, based on her identity, developing personality, mental life and experiences. As a result, she shows increasing embeddedness in human interactions and takes a fully reciprocal, participating role.

So, a distinct individual enters the human community by forming interactions which are at first relatively simple and then later more complex emotional, social and moral engagements. But notice that the extended form of humanity entails that an identifiable individual who will at some stage be a rational social being with full moral rights is in existence from very early on. Thus, from implantation the individual participates in an interaction which normally leads to full moral engagement. Because that individual has moral significance at its point of full human engagement, all phases of that individual share the moral properties involved.

The individual can therefore be regarded as part of the moral community at all stages of development and as becoming increasingly embedded in a more complex and compelling way as it develops, so that at some point it realises the mode or form of being which is the basis of its extended moral properties.

\section{Summary of the present argument}

We can now justify a relative sanctity for all human life. The justification is that to violate that life does violence to a basic feature of our moral attitudes.

This sanctity is attached to the human form as a whole where that form is viewed in a longitudinal sense and therefore present from conception and onwards throughout an entire life (13). The basis of this moral value is the human ability to interact with others in those situations where moral sense and morality are grounded (14).

All phases of the longitudinal form of a human being are aspects of the morally valued (unitary) whole and therefore all phases are morally valued in the same way. As the preimplantation period, whilst having no component of interaction, is part of that whole the preimplantation embryo is also seen to have moral value. Thus we conclude that serious consideration is due to anything which affects human life from fertilisation until death because moral weight is attached to what is being destroyed whenever a human life is terminated. So, where embryonic human life is balanced against the rights of another human being, decisions should not be taken lightly. (More about this later.)

\section{Questions and caveats}

In our society we draw lines. Western society says that adolescence begins with the onset of the teenage years; in the law an individual becomes a legal adult for some purposes on her eighteenth birthday and for others on her sixteenth (15). This encourages us to appeal to more occurrently realised properties and to favour a system where moral status is seen to be derived from the individual's stage of development. But, despite claims to the contrary (16), these lines are for convenience and, although each has a rationale, the exact points are largely arbitrary.

The development to adult form is a progression through a series of stages which merge into each other. There is a continuity of growth from blastocyst to born child, to adult and further. Because of this continuity it is impossible to identify specific points where significant change occurs. For instance, it is not possible to identify the specific point in time when the child ceases and the adolescent begins, or the adolescent ends and the adult begins. Therefore, we can see that it is more accurate (but also less convenient as far as the law is concerned) to say that form changes gradually over a period of time rather than changing suddenly. These points are familiar from arguments by Michael Tooley (17) and Bernard Williams (18).

When we add the premise that moral value attaches to the total (longitudinal) form in virtue of its most clearly morally endowed points we can see that moral (and legal) consideration is due to a human being from the beginning of the process until the end.

Against this one could argue that mere physiological interaction is not sufficient to give moral significance. It could be said that the social or rational element must be included before significance is properly ascribed (even at a minimal level). If physical interaction alone were morally significant we would be faced with the dilemma of having to treat an attached parasite, such as a tapeworm, with the moral consideration given an embryo or fetus. But this neglects the longitudinal 'form of a person'. There is a fundamental difference in form between a tapeworm and a human organism: an internal parasite simply grows and reproduces further parasites but a human embryo becomes a person with an interactive role in a human community. This creates a moral difference.

The same applies to a blastocyst which forms a hydatidiform mole instead of an embryo; it does not have the intrinsic potential to become a human being. Of course, given present medical technology, one cannot ascertain, prospectively, which will develop to term, which will spontaneously abort and which will become hydatidiform moles. Therefore all blastocysts must be considered to have the same moral status until the time when overall longitudinal form can be determined. In some cases this will not be until after birth.

Notice that we have given a new thrust to the 'potentiality argument' by relating attitudes to the individual at any given time to the attitudes to the total process of which that individual stage is an essential part. This, as we have noted, is continuous with other 
aspects of moral, legal, indeed general thinking. For example taking a piece of paper from somebody's desk is much more serious if the piece of paper is a match ticket to a cricket test than if it is a nondescript scrap of notepaper. The nature of the act depends not only on the act itself but also on its role in a total human situation over time.

A 'total process' approach has the right implications for other problem cases. For instance it allows us to act consistently towards individuals who are asleep, under anaesthesia or in reversible comas. Knowing that the individual has both a past ability and a potential future ability to interact in a moral and social community one can credit that individual with default intentional interests which the present circumstances do not allow her to express (19). It also makes 'moral room' for a policy of 'letting die' with regard to severely malformed neonates such as anencephalics where the presence of significant interaction is impossible and the totality involved is, in important repects, very different from that in the case of a 'normal' person.

Individuals who live in isolation (for instance marooned on a desert island), and therefore in the absence of interaction, are similary included under the present model, despite their lack of occurrent social relatedness. Their capacity to interact if the isolation is ended, inherent in the form of that individual, is intrinsically the same in type as that of fully moral beings and therefore they share the properties on which moral significance is grounded.

However, an excessively cognitive reading of morally significant interactions leads to problems. If one's ability to think and interact/communicate were to be graded, the individual whose form included the ability to interact on some yet to be defined 'higher plane' than others would be more important than other human beings. Perhaps a person whose total form included being a university professor would be more significant than an individual who was mildly intellectually handicapped. This immediately suggests an elitist attitude congenial to 'ivory towered academics' but not to 'normal' people. It does not seem to be a valid way to arrive at a conception of the person as the bearer of moral value. And, who is to say whether interaction with a three-month-old baby by nose-touching and noises is more or less valuable than a philosophical discussion with a twelve-year-old? We must beware of placing gratuitous value judgements on the type of interaction occurring. They are different types of interaction yet have both intrinsic value and value because they are parts of valued wholes, wholes which at some stage participate in moral interactions.

The moral significance of the age at which an individual dies can also be related to the natural unfolding of human form. We intuitively feel more sorrow at the death of a seven-year-old than that of a seventy-year-old, despite there being no difference in their moral value. Our different reactions are understandable. The death of a seventy-year-old is more consistent with the total form of humanity whereas the death of a seven-year-old does greater violence to the form which we value.

The question of the status of animals is also pertinent to the discussion. We see interactions between animals and humans. These are often complex and not infrequently of a similar nature to that seen between two human beings. If we are not to place value judgements on either the type of interaction or the species involved then it would seem that we have to consider animals in a similar, (potential/relational based) light to humans.

But the death of a human touches more closely the form that we value than the death of an animal. The form of an animal does not include a phase of full moral interaction, although at a minimal level some animals may interact with us as fully as do individuals with severe intellectual handicaps. Our reasoning is sensitively tied to many aspects of form, including bodily resemblance. In the case of some severely handicapped infants this inclines us to greater moral concern than, perhaps, is well-grounded (7).

However, this analysis seems to suggest that infanticide is no worse than contraception using the 'morning after' pill. This is decidedly counterintuitive, and in pursuing the issue we come across an already encountered feature of human reasoning. We reason on the basis of total processes, not moments in being. It seems rational to regard a setback at an earlier, indeed vestigial stage of a process as being of much less moment than when things have developed more fully (compare a mechanical failure on the number one spot of a formula one grid as compared to the final lap of the race when one is leading). Yet this seems to counter the intuition justifying our reaction to death at different ages (see above). The 'violence to overall form' argument appears to mitigate against early termination whereas the 'natural investment' reasoning is more tolerant. Here it seems that we cannot easily opt for a single moral precept to capture the subtlety of our natural reasoning.

Our attitudes are based on the total form of a human being and thus our moral reactions to events at any stage take account of the relationship between that stage and the whole. But also, we take reasonable note of the extent to which a process is realised when assessing the harm done by interrupting that process But this latter claim does not strip all value from a very early stage of the total process even if it gives it lower value than a more fully formed stage. A possible reconciling strategy would therefore be to include the 'degree of realisation' intuition into an understanding of our attitude to the totality of a human life.

Thus we can see that it is right that a pregnant woman has the greater claim to life because of her present ability to interact with others in the human community. There is a much more fully formed process or morally important individual 'cut-off' when one kills a developed human being. This does not negate the moral weight of a fetal life but merely ? suggests that in certain circumstances the risk to the 
mother is of greater moral weight. But, on this view, because the embryo is morally significant the risks posed to the mother by pregnancy must be significant or else an abortion cannot be morally justified (20).

This is not to say that a fourteen-day-old embryo has a less human form than a fetus of twenty weeks gestation which would thereby place different values on the individuals concerned. It is rather to acknowledge that even though moral significance is conferred on an individual at all stages of her development, it does not follow that all actions towards her, which are of the same type, have the same ethical and moral connotations at all stages.

The present 'total process' view of potentiality allows us to understand the intuition that we should preserve embryonic or fetal life. Because the typical human life is part of a temporal continuum, which includes embryonic and fetal life they are both valued as parts of the whole.

Finally the total process approach is immune to the standard objections to potentiality. Potentiality suggests that we should give ova and sperm the same moral significance as human beings. But this fails to take account of the individuals involved. Gametes do have the potential to form a person, should they be brought together under the appropriate circumstances, but their separate existences do not constitute part of the development of a human being. (That they could start the development of a human being is a reason, on the present account, for not regarding contraception as completely devoid of moral interest.) A pool of gametes does not yet contain identifiable human individuals in whom a morally valued form (in the longitudinal sense) has been initiated. The interaction is not between complete human individuals in a human community but an interaction of 'partial individuals' in a context which differs from that discussed earlier.

\section{'New birth technologies'}

'New birth technologies' (NBT) form a test case for the present view.

It is now possible to use a number of techniques to bypass a woman's infertility and enable her to become pregnant, including artificial insemination with husband or donor sperm (AIH or AID), ovulation induction (OI), in vitro fertilisation (IVF) and the newer technique of gamete intrafallopian transfer (GIFT). There has been controversy about the use of these NBTs since their creation. This is especially so with IVF because of the need for external fertilisation and the problem of 'spare embryos'. Certainly, to infertile couples, the use of these techniques has great value, but is this a sufficient justification?

On the one hand, it seems that the value placed on human life provides an argument in favour of NBTs: they produce something which is precious and valued. The decision to enter into such a reproductive programme is rational and considered: the couple, who place high value on having a baby, are prepared to go to extraordinary lengths to do so.

On the other hand, NBTs are beset with problems. Artificial reproduction does not simply fulfil the desires of an adult it also manufactures humans and in doing so may trivialise the ability to reproduce (21). The ability to create human life in an artificial manner may undermine or even negate the value that the embryonic phase of the human form ought to be given. The high cost to the user of such techniques (in some countries at least) and the lengths to which one has to go to get access to them may induce the attitude that the babies produced are a commodity available to a highly motivated group of people with the ability to pay. We may come to view babies as 'tailor made products' to be produced to specifications (for example, gender), when and where wanted. These possibilities and their moral implications are unsettling. In addition NBTs carry significant risk of multiple pregnancy (see fig 1 (22)). Multiple pregnancies, particularly those of quadruplet or greater (high-order), carry high risk to the health of both the fetuses and the mother. Because all these lives have moral worth it is inappropriate that such risks should be taken.

NBTs create the situation where multiple lives are at risk. Because of this we cannot easily assimilate the embryos to survivors in an overcrowded lifeboat. Therefore, we cannot argue that there is no problem because a hypothetical rational negotiation justifies an impartial selective reduction (the Rawlsian model (23)) and provide an ethical solution to a medically-created problem of high-order pregnancy. In the case of NBTs one has control, so to speak, over whether or not the lifeboat is set out to sea. It is clear that deliberately setting the boat adrift with prior knowledge that some of its occupants must be destroyed, if any are to reach safety at a later stage, is a morally suspect choice to make (24).

But we can avoid some of these harms by controlling the aspects of NBTs which lead to the incidence of high-order multiple pregnancy (ie a pregnancy of four or greater). In fact there are already techniques available to achieve this control.

1) We can monitor the regimes for multiple oocyte stimulation used in the course of infertility treatments by ovulation induction. This may involve regulations controlling the situations in which the ovulating dose of human chorionic gonadotrophin (hCG) is given, restricting gonadotrophin dosage and prohibiting use in specific types of infertility.

2) We can restrict the number of embryos transferred in an IVF cycle to a maximum of three (possibly even two) to eliminate the risk of a quadruplet pregnancy.

3) We can restrict the number of oocytes transferred in a GIFT cycle to a maximum of three (or two) for the same reason.

Therefore we conclude; firstly, that we ought to pay ethical regard to in vivo embryos. Secondly, if NBTs 
Figure 1

Table showing the risk of multiple pregnancy of varying sizes according to the type of pregnancy

\begin{tabular}{|c|c|c|c|c|}
\hline Procedure & Multiple & Twin & Triplet & Quad+ \\
\hline $\begin{array}{c}\text { clomiphene citrate } \\
{ }^{\star} \mathrm{hCG} \\
\# \mathrm{GnRH}\end{array}$ & $\begin{array}{l}7.2 \\
27.9 \\
5-7\end{array}$ & 20.4 & 5.3 & 2.1 \\
\hline $\begin{array}{c}\text { IVF } \\
\text { GIFT } \\
\text { natural pregnancy }\end{array}$ & $\begin{array}{l}22.6 \\
33.3 \\
1.2\end{array}$ & $\begin{array}{l}19.0 \\
21.2 \\
1.1\end{array}$ & $\begin{array}{l}3.5 \\
9.0 \\
0.01\end{array}$ & $\begin{array}{l}0.1 \\
3.0 \\
0.0001\end{array}$ \\
\hline
\end{tabular}

are to be used to create embryos (this in itself is debated) they ought to be equally available to all. Thirdly, given that embryos are phases of that totality which is a morally significant form, there ought to be ethical guidelines and practices controlling the medical production of in vivo embryos through the use of NBTs.

These constraints emerge from the regard we are obliged to attach to the form of humanity and in that sense seem to justify rights for embryos which do not allow us indiscriminately to 'mess around with them' without regard for ethical constraints.

Nicola Poplawski is a final-year medical student and ethics research student and Grant Gillett is Senior Lecturer in Medical Ethics, the Bioethics Research Centre at the University of Otago in Dunedin, New Zealand.

\section{Acknowledgement}

We would like to acknowledge the support of the New Zealand Medical Research Council in undertaking this study.

\section{Postscript: embryos and ethics}

Since completion of this paper we have discerned a further argument about embryos and their 'rights'. Human beings have both general and individual properties and, in different contexts, these differentially dictate our moral choices. We can say of an identifiable human being who has her own preferences and attitudes to life events that those individual choices, that her autonomy, ought to be respected. In this sense she has individual rights. But embryos, although they may share some of the moral status that we accord to human beings because they are part of the totality which is a human being are not plausible candidates for such rights. Their rights can therefore be thought of as general, relating to nonindividuated beings of a certain type who are, in one sense, substitutable for each other. With such beings we can look at a situation in terms of its total valueoutcome for beings of that type. Thus any individual of that type only has rights as an instance of the morally significant type which it is.

This allows us to defend ourselves against callous and dismissive moral attitudes to embryos in general, given that they are proper stages of morally significant beings, without defending the notion of individual and personal rights for any embryo. Any rights that an embryo has of an individual nature will attach to it only as a consequence of it having reached the stage where such attributions become intelligible.

This argument is supported by considering the indiscernability of substituting one (consanguineous) embryo for another prior to the stage of engagement with others as an identifiable individual. This cannot be materially (and therefore morally) relevant to anyone: not the mother or others because they do not and could not tell the difference; not the embryo because it cannot tell or have attitudes to anything. It is clear that the condition of substitutability and lack of individuation is steadily replaced by properties, both intrinsic and relational which ground individual rights, as the child develops and takes its (interactive) place in a human context.

\section{References and notes}

(1) Aristotle believed the attainment of the human form to be of great moral significance. Based on this belief, early law held the destruction of human life at any stage to be morally offensive, the penalties for such destruction being graded by the degree to which the human form had been reached.

(2) Gillon R. Philosophical medical ethics. Chichester: John Wiley and Sons for the British Medical fournal, 1985: 50.

(3) Skegg P D G. Law and medicine. Oxford: Clarendon Press 1984: 1-26.

(4) Hart H L A. Are there any natural rights? In: Waldron $\mathrm{J}$, ed. Theories of rights. New York: Oxford University 
Press, 1984: 77.

(5) On the other hand, constitutional/legal rights exist as a social control to ensure that a utilitarian balance is achieved.

(6) Scheffler S, ed. Consequentialism and its critics. New York: Oxford University Press, 1988.

(7) Gillett G R. Les enfant handicapes: un defi. Foi et vie 1989; LXXXVIII, 6: 63-75.

(8) See reference (2): 51 .

(9) Engelhardt H T. The foundations of bioethics. New York: Oxford University Press, 1986: ch 4: 104 onwards.

(10) Interpersonal in this context means 'between two persons at a reflective level'.

(11) Kuhse H, Singer P. Should the baby live? Oxford: Oxford University Press, 1985.

(12) A survey of the literature on pregnancy outcome reveals that for a naturally conceived pregnancy, there is an approximately 85 per cent chance that the conceptus will implant and be detected as a biochemical pregnancy by beta-hCG assay, approximately 54 per cent of conceptuses progress to clinical pregnancy and approximately 46 per cent to term. Most clinical abortions (those losses of clinically detected pregnancies) occur in the earlier stages of pregnancy. As a pregnancy becomes later term it is less likely to terminate in spontaneous abortion.

(13) It is interesting to note that such an interpretation has recently been adopted by the Danish Parliament. Law changes have led to the establishment of an ethical council whose work is to "build on the basis that human life takes its beginnings at the time of conception'. Holm S. New Danish law: human life begins at conception.
Fournal of medical ethics $1988 ; 14: 77-78$.

(14) Wiggins D. The person as object of science, as subject of experience, and as locus of value. In: Peacock A R and Gillett G R: Persons and personality. Oxford: Blackwell, 1987: 56-74.

(15) There is no age limit below which a woman is not entitled to make decisions for her offspring. This acts to create the situation where a thirteen-year-old can decide whether or not her baby should have an operation but not that she herself should.

(16) Buckle S. Biological processes and moral events. Fournal of medical ethics 1988; 14: 144-147.

(17) Tooley M. Abortion and infanticide. Philosophy and public affairs 1972: 2, 1; 37-65.

(18) Williams B. Which slopes are slippery? In: Lockwood M, ed. Moral dilemmas in modern medicine. Oxford, New York: Oxford University Press, 1985: ch 6: 126-137.

(19) Gillett G R. Reply to J M Stanley: fiddling and clarity. Fournal of medical ethics 1987; 13: 22-25.

(20) Social policy, of course, involves factors other than morality.

(21) Jones D G. Manufacturing humans: the challenge of new reproductive technologies. Leicester: Inter-varsity Press, 1987.

(22) These figures are gathered from a wide range of journal sources, the data of which was combined to give overal! figures.

(23) Rawls J. A theory of justice. Oxford: Oxford University Press, 1972.

(24) Poplawski N K. An ethical issue for reproductive technologies. Asia-Oceana journal of obstetrics and gynaecology 1990; 16: 291-296. 